\title{
“A RECEPÇÃO DOS 'PRINCIPIOS DE DIREITO MERCANTIL E LEIS DE MARINHA', DO VISCONDE DE CAIRU, PELOS COMERCIALISTAS BRASILEIROS DOS SÉCULOS XIX E XX"
}

“THE RECEPTION OF VISCONDE DE CAIRU'S 'PRINCIPLES OF MERCHANT AND MARITIME

LAW' AMONG BRAZILIAN COMMERCIAL LAW SCHOLARS OF THE 19TH AND 20TH CENTURIES”

Ruy Pereira Camilo Junior ${ }^{*}$

\begin{abstract}
Resumo:
$\mathrm{O}$ artigo constata que, após o longo período de esquecimento que se seguiu à promulgação do Código Comercial de 1850, a obra fundadora da literatura jurídica nacional - os "Principios" de Cairu - foi resgatada pelos comercialistas brasileiros, em um momento histórico de revalorização do papel da doutrina. A releitura deste autor representativo da crise do Antigo Regime não pode, no entanto, ser feito de modo anacrônico, sendo imprescindível compreender sua cosmovisão.
\end{abstract}

Palavras-chave: Cairu. Princípios de Direito Mercantil e Leis de Marinha. Recepção. Doutrina Comercialista.

\begin{abstract}
:
The paper points out that, after a long period of oblivion following the entry into force of the 1850 Commercial Code, Cairu's "Principles" - founding work of the national legal literature - was rescued by the Brazilian Commercial Law scholars, in a historical moment when legal scholarship was being reassessed. The new readings of an author representing the Ancien Régime crisis can not be anachronistic, but demands the understanding of his cosmovision.
\end{abstract}

Keywords: Cairu. Principles of Commercial and Maritime Law. Reception. Commercial Law Scholarship.

1. O destino da obra de um fundador do império

1.A. O problema geral da recepção da obra de Cairu

"Contra a verdade dos povos missionários, definida pela sagacidade de um antropófago, o Visconde de Cairu: - É a mentira muitas vezes repetida"

Oswald de Andrade, Manifesto Antropófago.

"O passado é um país estranho"

L. P. Hartley

\footnotetext{
* Advogado. Mestre e Doutor em Direito Comercial pela Faculdade de Direito da USP. Pós-Graduado em Análise Econômica pela FIPE/OEB. E-mail: ruy.camilo@camilo.adv.br. 
José da Silva Lisboa, o futuro Visconde de Cairu, ${ }^{1}$ foi uma referência intelectual do Brasil Joanino e do Primeiro Reinado. Isabel Lustosa chama-o de "Ruy Barbosa do Século XIX" (LUSTOSA, 2000, p. 25), para dar a dimensão de sua figura na então nascente opinião pública brasileira.

Um homem ilustrado, de uma das primeiras turmas formadas após a reforma pombalina da Universidade de Coimbra - onde adquiriu uma postura antijesuítica jamais superada -, veio posteriormente a estudar as obras de Burke e de Adam Smith, mantendose politicamente ultraconservador, mas economicamente liberal. ${ }^{2}$ Sob o espectro da Revolução Francesa, parte de sua extensa obra impressiona pela demofobia ${ }^{3}$ e pela defesa, em um primeiro momento, do absolutismo real português, e depois, da centralização monárquica do nascente império brasileiro. Outra parte encontrava-se alinhada com o pensamento mais inovador de seu tempo: aí se inscrevem suas obras econômicas - com o repúdio aos institutos mercantilistas erigidos por Pombal - e seus "Principios de Direito Mercantil e Lei de Marinha", livro fundador da literatura juscomercialista moderna em Portugal e obra inaugural do direito brasileiro.

O presente artigo investiga a forma como este livro foi recepcionado pela doutrina jurídica nos séculos XIX e XX, mostrando que as visões dos historiadores e dos juristas sobre Cairu eram diametralmente opostas, e inverteram-se ao longo do tempo.

No campo historiográfico, a imagem de Cairu era exaltada no século XIX, por seu papel na abertura dos portos, tida como verdadeira independência econômica do Brasil, e por sua participação nos eventos da independência e da consolidação do Primeiro Reinado. Era glorificado como um dos fundadores do império. No entanto, no Século XX, Silva Lisboa transformou-se em verdadeira bête noire do pensamento social brasileiro, que o considera defensor do imperialismo inglês e do autoritarismo monárquico.

Já o Cairu jurista teve uma trajetória diametralmente oposta. Após um período de muitas edições dos "Principios" - que gozavam de autoridade como verdadeiro código mercantil, em época em que ainda se pensava na doutrina como fonte de direito -, a obra jurídica de Silva Lisboa é lançada no esquecimento pelo advento do Código Comercial Brasileiro de 1850. Veremos que sua doutrina e seu nome não são referidos nos principais comentadores daquele diploma legal, no século XIX.

1 Embora só tenha recebido o título de Barão em 1824 e o de Visconde de Cairu em 1826, neste artigo José da Silva Lisboa será chamado de Cairu independentemente da época de sua vida a que estejamos nos referindo. De igual modo, transcrições de textos antigos serão adaptadas à ortografia contemporânea.

2 Coincidindo com o pensamento dominante na elite imperial, o liberalismo de Cairu convivia paradoxalmente com a tolerância à escravidão. Aterrorizado com a experiência haitiana, defendia ele uma abolição gradual, após a prévia "educação da escravatura".

3 Ao ser acusado de desrespeitar a opinião publica, Cairu retrucou: "Não conheço esta senhora" (CABRAL, 1881, p. 44). 
No século XX, após o silêncio de mais de meio século, o Cairu Jurista passa a ser exaltado pelos Comercialistas, que louvam o pioneirismo de sua obra, e afirmam a perenidade de algumas de suas lições. Ao contrário dos pensadores sociais que o vilipendiam, os autores do Direito Comercial do Século XX só se referem a ele com respeito e deferência.

O que explica o silêncio oitocentista dos comercialistas sobre Cairu? Por que, quando ele é rompido, a recepção da obra de Cairu pelos juristas do século XX faz-se de modo quase ufanista, em total dissonância com o tom severo e crítico dos pensadores sociais que lhes são contemporâneos.

As explicações podem ser encontradas dentro do próprio pensamento jurídico: a) o predomínio de uma abordagem exegética do Código Comercial, com a consagração do comentário e anotação ao texto legislativo como modalidade literária dos comercialistas do século XIX, é a razão da omissão do nome de Cairu dos estudos da época, bem como das escassas referências doutrinárias nessas obras; b) o advento do positivismo científico e da pandectística revalorizaram o papel da doutrina, na sistematização da matéria e na construção de conceitos; c) de modo específico, no campo do direito comercial, a doutrina do século XX recupera seu protagonismo pois lhe compete sistematizar sua matéria, considerando o advento em 1916 de um Código Civil moderno, ao lado do vetusto Código imperial, e a proliferação de legislação extravagante. A modalidade literária que atenderá a essas exigências serão os extensos Tratados de Direito Mercantil ou Comercial que se vulgarizam; d) a invocação do nome de Cairu legitima este renovado papel da doutrina, conferindo-lhe o peso da tradição e elevando-o a verdadeira figura tutelar dos comercialistas; e) A referência a Cairu faz-se, em geral, de modo retórico e anacrônico. Ele é pouco citado no enfrentamento de questões postas pela dogmática juscomercialista.

Talvez falte a esta doutrina novecentista a percepção clara dos exegetas do século anterior de que havia uma ruptura e uma descontinuidade entre o trabalho deles e o de Cairu. Não se cuida apenas de uma desatualização derivada da superação dos alvarás e regimentos citados nos "Principios" pelo Código Comercial ou pelas leis que se lhe seguiram: o direito para Cairu é distinto do direito do século XX em algumas concepções fundamentais.

Para Cairu, o direito inseria-se, ao lado da economia, no campo da filosofia moral, razão pela qual sua obra jurídica tinha um nítido viés pedagógico, e sua argumentação é recheada de argumentos éticos e econômicos. Tem o autor visão extremamente crítica dos processos judiciais. O propósito de Cairu era organizar e sistematizar as várias fontes que coexistiam no mundo pré-codificação - doutrinas, costumes, alvarás régios -, devendo sua obra servir de fonte do direito até o advento de lei que regesse o direito comercial e marítimo. Funcionando ainda como fonte de direito, a obra doutrinária dirigia-se aos 
comerciantes de modo direto e a eles era dedicada e dirigida. Os institutos de direito mercantil não eram arbitrários, mas decorriam da natureza, em especial da sociabilidade inerente ao homem, repudiando-se as visões contratualistas e individualistas da sociedade. $\mathrm{O}$ estudo do direito das gentes e dos usos e costumes da Europa apontariam essas soluções de direito natural, sendo certo que o comércio unia os homens em uma grande família.

\section{B. Cairu: um homem entre dois tempos}

A vida de Cairu, tal como sua obra, tem fundamentos sólidos na tradição, mas espelha uma época revolucionária na Europa e no Brasil. Ele foi um homem de um período de transição, marcado por contradições.

Era demófobo, embora de origem humilde. Baiano, filho de mãe parda e pai mestre de obras, teve de trabalhar em Coimbra como docente substituto de grego e hebraico para pagar parte de seus estudos de Cânones e Filosofia. Retorna à colônia e é nomeado ouvidor em Ilhéus, crendo que "a simples sombra do poder régio inerente à magistratura" bastaria para dar efetividade a seus poderes. Inicia devassas e cobranças de dívidas com a coroa. Passa a ser alvo de representações e reclamações graves, que o levam de volta a Salvador, profundamente frustrado. No entanto, continua sua vida de magistrado e funcionário, acumulando vários cargos e vencimentos: deputado e secretário da Mesa de Inspeção do Comércio da Bahia (órgão que fiscalizava a qualidade do açúcar, fixava preço de alguns produtos e geria falências), Professor Régio de "Filosofia Racional e Moral" e "Grego" em Salvador e de "Economia Política" no Rio de Janeiro. ${ }^{4}$

Como funcionário régio, no início de sua carreira não questionava o status colonial, afirmando não serem fáceis de encontrar "colônias mais favorecidas pela Metrópole", dada a baixa tributação (KIRSCHNER, 2009, p. 58). Sem se deixar levar pelo entusiasmo inicial da elite brasileira pela Revolução do Porto, foi um dos protagonistas do Fico e da Independência, e um dos principais divulgadores da tese de que as Cortes queriam recolonizar o Brasil. Teve papel ativo na abertura dos portos em 1808, influenciando o Rei por intermédio de D. Fernando José de Portugal, que fora governador da Bahia e Vice-Rei do Brasil, e de quem era amigo. Defendeu o Tratado de Livre Comércio com a Inglaterra, escrevendo, em 1810, "Refutação das Declamações contra o Comércio Inglês". Desde a década de 1790 era partidário do anglófilo Rodrigo de Souza Coutinho, seu "benfeitor", em suas palavras.

\footnotetext{
$4 \quad$ Isso após a chegada de Dom João, quando se muda pra o Rio. O Decreto que criou a cadeira declarava que sem a ciência da economia "se caminha às cegas e com passos muito lentos e às vezes contrários em matéria de governo". Cairu não chegou a dar aula alegando falta de interesse dos alunos, preferindo escrever obras econômicas de divulgação.
} 
Em síntese, era defensor simultaneamente do liberalismo econômico e do absolutismo. 5 Seu liberalismo não era "ideia fora do lugar", na acepção de Roberto Schwarz, mas correspondia ao reclamo da elite baiana, que desejava a liberdade comercial para poder vender seus produtos ao melhor preço possível. Mas tampouco era Cairu portavoz das elites, pois se indispôs com muitos comerciantes que pretendiam privilégios, ainda imbuídos por uma concepção mercantilista, que vicejara sob Pombal.

Foi ele o autor do primeiro livro publicado no Brasil - "Observações sobre o Comércio Franco no Brasil”, e o que mais publicou na Imprensa Régia. Era divulgador das ideias de Burke - de quem traduziu obras - e de Smith. No entanto, como Desembargador da Mesa do Desembargo do Paço no período joanino, foi nomeado Censor Régio, vetando a publicação de Gibbons e das "Cartas Persas" de Montesquieu, autor que tanto respeitava.

Com a idade, Cairu torna-se crescentemente conservador. No Primeiro Império, defendeu o fechamento da Constituinte de 1824. Votou contra a liberdade religiosa e o júri nos processos criminais (único voto contrário nessa matéria). Dentre as várias citações reacionárias que se poderia extrair de seus discursos, artigos e livros, tomese como exemplo aquela usada como epígrafe de relevante obra de Isabel Lustosa sobre a imprensa do Primeiro Reinado: "A liberdade civil e da imprensa tem sido justamente comparada ao vinho espirituoso, o alimento substancial que atordoa as cabeças fracas e arruína os estômagos débeis". (LUSTOSA, 2000, p. 6).

Já sexagenário, polemiza na belicosa imprensa do primeiro império (na qual o próprio D. Pedro I escrevia sob pseudônimo), publicando, na década de 1820, 9 jornais e 42 panfletos. ${ }^{6}$ Curiosamente, mesmo seus adversários reconheciam sua cultura e erudição: diziam que sua cabeça era "uma biblioteca em desarranjo" e que devia recolher-se à Santa Casa (KIRSCHNER, 2009, p. 219). José Bonifácio, em versos, chamou-o de "charlatão idoso (...) que escreve folhetos a milhares, que ninguém lê, porque ninguém entende”. O Senador Alencar afirmava que "sua literatura, posto que vasta, quando muito poderia ser própria para o século passado, até 1789 ". 7 Quando de seu falecimento, seu antagonista Mont'Alverne, grande orador sacro, afirma que "morrera um grande homem, apesar de que a sua cabeça não passava de uma gaveta de sapateiro" (CABRAL, 1881, p. 43).

Escrevia Cairu que o "dever do soberano é, como pai justo e sem odiosas predileções, proteger com imparcialidade a todas as ordens e todos os indivíduos da nação".

6 A atuação panfletária de Cairu é amplamente analisada por Isabel Lustosa, no vasto panorama que apresenta da imprensa do periodo da independência, em "Insultos Impressos". Destacam-se os embates de Cairu com Hypolito da Costa, Cypriano Barata, e os integrantes do que o futuro visconde denomina a "facção gálica", em especial Gonçalves Ledo, João Soares Lisboa e Januário da Cunha Barbosa.

7 A idade é aspecto central da construção da imagem de Cairu, tanto por ele e seus apoiadores - que o apresentam como um patriarca sábio-, quando por seus detratores, que o tacham de senil, embora reconheçam sua erudição". 
Um traço de coerência e constância ao longo de sua viva foi a lealdade à Dinastia Bragança. Permaneceu ao lado de D. Pedro até a abdicação, quando sua casa foi apedrejada.

As severas críticas que lhe foram dirigidas - muitas vezes em revide - por Frei Caneca, Cipriano Barata, Hipólito José da $\operatorname{Costa}^{8}$ e outros liberais terminaram por influenciar a historiografia do século XX, explicando seu viés negativo a respeito de Cairu.

1.C. "Os principios de direito mercantil e leis de marinha"

Cairu escreveu 35 obras, elencadas por Cândido Mendes: cinco sobre comércio, duas sobre direito mercantil, seis sobre economia política, doze sobre política, cinco sobre religião e cinco sobre história. Estão registrados ainda 522 discursos parlamentares, além de proposições, pareceres e intervenções.

Inaugurou sua produção com a publicação de 2 volumes dos "Principios de Direito Mercantil” em Lisboa, em 1798. À época, advogava na capital do Reino. Continuou se dedicando à obra na Bahia, embora se queixasse da falta de acesso a arquivos. ${ }^{9}$ Em 1802 voltou a Lisboa para realizar pesquisas finais na Real Junta de Comércio, e para tratar da publicação da obra completa na Tipografia do Arco do Cego, estabelecida pelo Ministro Rodrigo de Souza Coutinho para disseminar obras científicas.

Cairu escreve que a obra "não teve protótipo nem modelo" (KIRSCHNER, 2009, p. 133), sendo a pioneira em seu estilo e conteúdo em língua portuguesa. Ela é composta dos seguintes tratados: Dos Seguros Marítimos, Do Câmbio Marítimo, Das Avarias, Das Letras de Câmbio, Dos Contratos Mercantis, Da Polícia dos Portos e Alfândegas, Dos Tribunais e Causas de Comércio.

A oitava parte foi publicada em separado, como "Princípios de Economia Política".

Os materiais invocados por Silva Lisboa espraiam-se por mais de um milênio.

Dentre fontes por ele referidas acham-se o Corpus Iuris Civilis, a Lex Rhodiae, o Consulato del Mare, as Ordenações de Wisby e da Hansa, as Ordenações do Reino, os Assentos da Suplicação, as Ordenações da Marinha da França, o Código

8 No período joanino, Hipólito José da Costa, no "Correio Brasiliense", ironiza o liberalismo de Cairu, que teria mostrado ao mundo "a grandíssima liberdade que há no Brasil de falar bem e elogiar os ministros e o governo".

9 Ferreira Borges, nas "Instituições de Direito Cambial," criticava o tratamento dado por Cairu às avarias e a omissão sobre a forma de seu cálculo, afirmando que o autor baiano não pudera consultar o que havia de melhor sobre a matéria. No Prólogo aos Princípios de Economia Política", Cairu lamenta que não se encontrasse "perto das grandes luzes europeias". 
Marítimo da Rússia da Catarina II. Em edições posteriores, cita os Códigos de Comércio da França e da Espanha e o Projeto de Código Comercial de Portugal.

No campo da doutrina, cita dos romanos (Tito Lívio, Cícero, Suetônio, Juvenal) a Camões; dos Jusnaturalistas (Grocio, Vattel, Heinecio) aos comercialistas do início da época moderna: Pedro de Santarem ou Santerna, Stracca, Ansaldo, Casaregis; Savary, Emerigon, Baldasseroni. Estão igualmente presentes autores do século XVIII das mais variadas áreas, como Montesquieu, Blackstone, Mansfield, Pardessus, Ferreira Borges, Smith, Hume, bem como autores ingleses e franceses com obras modernas sobre seguros, como Millar e Allan Park.

Depois dos "Principios", voltou aos temas de Direito Mercantil em 1832, com a obra de 100 páginas intitulada "Regras da Praça ou Bases do Regulamento Comercial, conforme os Novos Códigos de Comércio e Legislação Pátria”.

\section{A recepção da obra de Cairu}

\section{A. A visão de Cairu na historiografia}

Não obstante ter sido alvo preferencial da imprensa liberal no Primeiro Reinado, Cairu viu-se consagrado como um dos patriarcas brasileiros e um dos fundadores do Império, na historiografia do século XIX.

Constam dezenas de menções ao nome de Cairu no v. 3. tomo 5, da História Geral do Brasil, e na História da Independência do Brasil, de Francisco Adolfo de Varnhagen. Para o Visconde de Porto Seguro, Cairu "grangeou a veneração pública pela muita firmeza de caráter, aquilatada virtude e nobreza de caráter".

Tudo muda na contemporaneidade. Os pensadores do Brasil no Século XX tiveram sua visão de Cairu marcada pelo tom carregado da imprensa liberal pósindependência, e transformaram-no em alvo preferencial de ataques, sob os mais diversos ângulos.

José Honório Rodrigues chama-o "Grande servidor dos soberanos $e$ dos ingleses, o Sipaio-mor da História do Brasil". Antônio Cândido considerava-o um "palaciano na adulação". Celso Furtado contrasta-o com Alexander Hamilton, "paladino da industrialização", que "advoga e promove uma decidida ação estatal de caráter positivo", enquanto Cairu "crê supersticiosamente na mão invisível” (FURTADO, 2000, p. 106-107). Sérgio Buarque de Holanda critica-o por afirmar que a quantidade de inteligência é mais importante para a prosperidade da nação do que a quantidade de trabalho: essa Inteligência seria anti-moderna e 'simplesmente decorativa', por contraste ao trabalho físico, numa "sociedade de coloração aristocrática e personalista" (HOLANDA, 1991, p. 52). Era também criticado por Otávio Tarquínio de Souza, em suas várias obras sobre os fundadores do Império. 
Defendiam-no uma minoria de autores, como Tristão do Athayde e Santiago Dantas. O primeiro considerava-o "figura da história universal" e "Patriarca da nossa independência moral e intelectual". (ATHAYDE, 1956, p. 43). O segundo apontava para a excepcionalidade de sua cultura até quando considerados os ambientes europeus. Embora diga que os "principios de direito mercantil" sejam "obra hoje considerada muito imperfeita" (DANTAS, 2002, p. 10), afirma que Cairu aparece, "na galeria de nossos patriarcas, como o espírito mais consciente dos problemas econômicos do seu tempo, e como arquiteto de algumas de suas mais felizes soluções" (DANTAS, 2002, p. 5). ${ }^{10}$

Registre-se que esses poucos e ilustres defensores de Cairu são autores de marcada formação jurídica. Talvez não seja uma mera coincidência, como se verá infra.

\section{B. Recepção da obra de Cairu pelos comercialistas}

2.B.1. A autoridade dos "Principios..." como verdadeiro Código Comercial.

Ferreira Borges afirmava que Lisboa foi "o primeiro jurisconsulto comercial que escreveu em nossa linguagem”. "Suas obras foram Código Mercantil para Portugal até a publicação do Código Comercial Português" (FERREIRA, 1960, p. 69). Não se cuida de mera metáfora. No direito pré-codificações, a doutrina organizava e sistematiza as múltiplas e contraditórias fontes, dos costumes aos assistemáticos regimentos reais e decisões normativas de tribunais. Por isso, Cairu dirige-se diretamente aos comerciantes, e especialmente à mocidade que desejava se iniciar no comércio.

Os "Principios" tiveram outras edições em 1815, 1817, 1819, e 1828. Segundo Bento da Silva Lisboa, filho de Cairu e autor de primeiro trabalho biográfico sobre ele, houve ainda uma edição em Londres.

Convidado em 1809 pela Real Junta de Comércio para elaborar um "Código Nacional de Jurisprudência Marítima", produziu um plano e iniciou um esboço, apresentado em 1826, e que foi parcialmente aproveitado para o Código de 1850. Cairu justificara seu insucesso dizendo que a tarefa excedia suas forças. (ALMEIDA, 1874, p. 10).

Curiosamente, não foi ele nomeado em março de 1832 para a Comissão de Elaboração do Código Comercial. O Jornal $A$ Verdade lamentou, pois "foi o primeiro que escreveu sobre matérias de comércio na sua excelente obra Principios de Direito Mercantil, citada em todos os tribunais da nação (...) (o autor) era mais apreciado nos

10 Cite-se, ainda, com uma avaliação positiva, "Cairu e o Liberalismo Econômico", de Antonio Paim. Carregando nas tintas críticas "O Discurso Autoritário de Cairu”, de João Alfredo de Sousa Montenegro. A excelente obra de Tereza Cristina Kirschner mostra-se mais balanceada, enxergando o autor em seu contexto, e apontando as ambiguidades da ilustração portuguesa a que Cairu pertencia. 
países estrangeiros que na sua própria pátria” (KIRSCHNER, 2009, p. 278). O Ministro José Lino Coutinho, no entanto, atribuía a não nomeação a suas enfermidades. ${ }^{11}$

No entanto, a leitura da lista extensa de adversários atacados por Lisboa em suas polêmicas na imprensa e no parlamento, e sua posição de apoio ao Imperador até a data da Abdicação - tida por muitos à época como a verdadeira independência do Brasil -, melhor explica que a Regência não o tenha prestigiado com a nomeação para a Comissão, apesar de seus extensos conhecimentos em matéria de Direito Comercial. A propósito, Brasílio Machado, em alentado estudo sobre a formação do Código Comercial Brasileiro, publicado na Revista da Faculdade de Direito de São Paulo em 1910, afirma

É provável que, pertencendo o Visconde de Cairu ao Partido Caramuru que abrira luta sem tréguas ao partido moderado, donde saíra organizada a Regência, deixasse de ser convidado para colaborar no projeto de código. E, quando solicitado, não havia de estranhar que recusasse o convite. (OLIVEIRA, 1910, p. 12).

\section{B.2. O Silêncio dos Exegetas do Código Comercial de 1850}

Promulgado o Código, olvida-se a obra jurídica de Cairu. Candido Mendes dizia que ele "jaz entre nós desconhecido".

Cândido Mendes reedita-o em 1874. Justifica-se afirmando que havia pouca doutrina entre nós, e que mesmo as referências ao direito pré-codificação comercial seriam relevantes aos estudiosos. Observe-se que o editor não mais enxerga como destinatários da obra os comerciantes, mas sim os juristas. Esta é a razão por que se refere, em sua apresentação, ao leitor que seja "cultor da jurisprudência comercial". Curioso também é o fato de Mendes ter acrescido à sua edição um longo texto de sua autoria: uma introdução histórica do direito mercantil de 648 páginas, tal como escrevera, em sua edição das ordenações, capítulo extenso sobre a história do direito.

Ao justificar a reedição, menciona igualmente a participação de Cairu na independência, demonstrando o valor de sua imagem pessoal no século XIX:

A ortodoxia da doutrina, o senso jurídico, e a pureza da linguagem, qualidades sólidas que garantem do olvido um trabalho de préstimo, conta também em seu apoio a obra que editamos a circunstância do caráter privado do autor (...) e sobretudo os serviços eminentes que prestou à emancipação do Brasil desde o momento em que a Dinastia de Bragança aportou às nossas plagas. (ALMEIDA, 1874, p. 6).

11 Esta versão é aceita por Waldemar Ferreira em "Diretrizes do Direito Mercantil Brasileiro". 
Apesar da reedição dos Princípios, continua a obra a merecer o silêncio da doutrina oitocentista. Isso ocorre pela adesão dos comercialistas aos métodos da Escola da Exegese. A modalidade de literatura jurídica que predomina é o da mera anotação aos textos do Código Comercial, com escassas referências doutrinarias. Esta escola, amplamente hegemônica na França do século XIX, caracteriza-se por um verdadeiro monismo reduzindo todo o direito à letra dos Códigos Napoleônicos -, e uma metodologia pobre, apegada à literalidade dos dispositivos. ${ }^{12}$

O "Abecedario Jurídico-Comercial” (1861) compila, em ordem alfabética, as normas do Código Comercial, acrescida "dos assentos do tribunal do comercio da Capital do Império e das Opiniões do Instituto dos Advogados do Brasil a respeito da inteligência de alguns artigos do Código e de seus Regulamentos". Propõe-se seu autor, Joaquim José Pereira da Silva Ramos, a que a obra sirva de "fio de Ariadne para (os leitores) saírem do intrincado labirinto em que se vai abismando a nossa recente legislação comercial". Cairu não é citado: talvez deva permanecer no labirinto, junto ao minotauro...

O Código Comercial do Império do Brasil, de Salustiano Orlando de Araújo Costa, traz, para cada artigo do Código, notas de legislação extravagante e jurisprudência comercial. Sob a rubrica "concordância", aponta a norma específica de inúmeros códigos estrangeiros que tem correspondência ao tema tratado. Não se nutre ele da doutrina de Cairu.

Os "Aditamentos ao Código do Comércio", de Teixeira de Freitas, trazem principalmente subsídios jurisprudenciais. Sob o título de doutrina, o autor inclui, em geral, considerações de sua própria autoria sobre as normas em comento.

O Código Comercial Brasileiro Anotado, de Antônio Bento de Faria, tampouco inclui Cairu na Bibliografia constante de sua primeira edição (1902), ou no índice da $4^{a}$. edição. No entanto, é uma obra de transição, em que ganha muito mais espaço a doutrina do que nas obras anteriores. Bento de Faria cita poucos autores précodificação (menciona v.g., Casaregis, Stracca, Emerigon - sobre seguros - e Pothier). Predominam as referências aos comentaristas dos códigos comerciais europeus: Lyon Caen e Renault (extensamente citados), Ferreira Borges, (mencionado mais de 20 vezes), Pardessus, Vivante, Vidari e Thaller. Citam-se também monografias brasileiras de Direito Comercial, como obras de Carvalho de Mendonça sobre Falências e Warrants, e Inglez de Souza (Títulos ao Portador). ${ }^{13}$

12 Sobre a história da Escola da Exegese, e suas várias fases até a decadência que se inicia com os ataques emergentes da obra de François Gény, v. BONNECASE, Julien, La Pensée Juridique Française de 1804 à L'Heure Présente, 2 volumes, Bordeaux: Delmas, 1933.

13 Considerando o enfrentamento do tema do processo comercial, são ainda citados por Bento de Faria processualistas como Lobão e Ramalho. Dos civilistas, Bento de Faria cita Mello Freire, Coelho da Rocha 


\section{Mas Cairu será resgatado no Século XX.}

2.B.3. A apologia dos tratadistas da primeira metade do século XX.

Nos extensos e eruditos capítulos de "Direito Cambial Brasileiro - Estudo Teórico e Prático", publicados sequencialmente na Revista Forense, a partir de janeiro de 1905, José A. Saraiva faz algumas referências, no texto principal ou em notas de rodapé, aos "Principios de Cairu", resgatando seu nome, embora sem maior destaque.

No Século XX, entra em voga a publicação de aulas em formato de livro, de que ocorreram alguns exemplos no século anterior. No campo do Direito Mercantil, pode ser referida, como exemplo dessa literatura, o "Direito Comercial," de Inglez de Souza. O formato de aula, no entanto, é pouco apropriado para citações doutrinárias ou mesmo jurisprudenciais. Inglez de Souza não menciona Cairu na obra, embora se refira de modo genérico aos festejos que então se davam pelo primeiro centenário da Abertura dos Portos. Em outra oportunidade, proferindo o discurso inaugural do Congresso Jurídico Brasileiro de 1908, Inglez de Souza classificou-o como "o nosso primeiro e até hoje não excedido comercialista”. (MENDONÇA, 1937, p. 84).

É o início de uma série de loas que marcam os livros de Direito Comercial brasileiros. ${ }^{14}$ Em um movimento de retomada da importância da doutrina, Cairu é alçado a patrono dos comercialistas brasileiros.

O advento do positivismo científico leva a uma sistematização do ensino do direito e a um "estrito treino conceitual". Na Alemanha, a pandectística ganha relevo, dado o fato de, "na falta de uma codificação, o manual científico constituir a última instância decisória da prática do direito comum" (WIEACKER, 1980, p. 510).

De modo específico, no campo do direito mercantil, a doutrina passa a ter um papel chave para guiar a jurisprudência, pois deve: a) dar consistência à distinção entre os campos do direito civil e comercial, para definir a abrangência dos dois códigos. Seguem-se tortuosos esforços de conceituar a essência do ato de comércio; b) ao mesmo tempo, como o Código Civil tinha aplicação subsidiária à matéria mercantil, e o diploma de Clóvis era, em vários aspectos, muito mais moderno e avançado do que o vetusto Código do Império, deve-se buscar a harmonização na aplicação das normas; c) deve-

e os projetos de Clovis e Felício dos Santos. Estão igualmente presentes publicistas como Ribas e Pimenta Bueno, civilistas franceses da escola de Exegese como Aubry e Rau e Demolombe. Além da menção a Revistas jurídicas (como O Direito e a Revista da Faculdade de Direito de São Paulo), faz-se uso da jurisprudência, da legislação extravagante e das "legislações dos povos cultos".

14 Registre-se que, nos vários capítulos do Direito Cambial Brasileiro - Estudo teórico e prático, que José Saraiva fez publicar na Revista Forense, a partir de 1905, há algumas referências breves, em notas de rodapé, à doutrina de Cairu em matéria cambiária. 
se conciliar a crescente legislação extravagante, inspirada por teorias sofisticadas, nos campos de títulos de crédito, companhias, sociedades limitadas e falências.

A modalidade de literatura jurídica própria a todos esses papéis são os extensos tratados, em vários volumes, que abarcam toda a matéria de Direito Comercial. Estes tratadistas não deixam de invocar o nome de Cairu, como seu antecessor, legitimando seus esforços científicos e servindo-lhes de figura tutelar.

Deem-se alguns exemplos.

Carvalho de Mendonça afirma que Cairu e o português Ferreira Borges tiveram obras contemporâneas, "enxugando as penas quase ao mesmo tempo. O fulgor de seus livros mantem-se ainda em nossos dias (...). No plano lógico que seguiram, simplificaram e afastaram a confusão que os envolvia aos direitos comercial e marítimo". (MENDONÇA, 1937, p. 87).

Waldemar Ferreira transcreve, no volume I de seu "Tratado de Direito Comercial" não apenas o plano do Código de Comércio de Cairu, mas a íntegra de seu Relatório Preliminar, que se estende por 15 páginas, e que "permaneceu desconhecido por muito tempo". (FERREIRA, 1960, p. 74). ${ }^{15}$

Ascarelli afirmou a respeito os "Principios" de Cairu que "é o mais agudo e moderno Tratado de Direito Mercantil dos Fins do Século XVIII e princípios do Século XIX”. (FERREIRA, 1960, p. 69).

Alfredo Lamy, na apresentação da reedição da obra feita pelo Ministério da Justiça, em 1963, saúda os "Principios" como "primeira grande obra de nossa literatura jurídica". Afirma que embora apresente "as marcas indeléveis do envelhecimento de século e meio (...). As linhas básicas dessas instituições ali estão fixadas em toda a sua expressão e nitidez". Incorrendo em anacronismo, Lamy vincula a obra de Cairu à luta pelo desenvolvimento, ${ }^{16}$ o que, de certa forma, permite invocar o dito irônico de que as fontes podem ser torturadas até dizerem o que se quer ouvir...

Registre-se que a mesma idealização da figura e da obra de Cairu pela doutrina comercialista ocorre entre os economistas das últimas décadas. Autores glorificam Silva Lisboa "como um economista genial (estaria no mesmo plano de Adam Smith, teria influenciado Ricardo e até mesmo antecipado Keynes...)”. (ROCHA, 2001, p. 34).

\footnotetext{
15 Ferreira igualmente louva o trabalho de Cairu em suas palestras na Universidade de Lisboa, em 1933, publicadas sob o título "As Diretrizes do Direito Mercantil Brasileiro".

16 "Em verdade, na fase de desenvolvimento por que passa a vida econômica do país, e que exige, para sua ordenação jurídica, a modificação ou reestruturação de muitas das instituições tradicionais (...) crescem de interesse o conhecimento e a meditação da vida e da obra de Cairu. "E que, a qualquer observador dos nossos dias, se impõe a evidência da singular correlação entre a época que Cairu dominou com sua presença - da abertura dos portos, de crescimento econômico e da nossa independência política - com a luta que ora trava o país contra o subdesenvolvimento". (LAMY, 1963, p. 13).
} 
Marcante é, portanto, o contraste entre os vivas dos comercialistas e economistas a José da Silva Lisboa, e os apupos dos pensadores sociais do século XX.

No entanto, talvez falte aos comercialistas a percepção das rupturas e descontinuidades entre a obra de Cairu e a doutrina posterior à Codificação. Tal ruptura talvez fosse mais notada pelos exegetas do século XIX que, por isso, silenciaram sobre sua obra.

3. Descontinuidade da obra de Cairu com a comercialística posterior ao Código Comercial

3.A. Um direito integrado à economia, no campo da filosofia moral

3.A.1. Direito separado da religião

Na obra de Cairu, o direito não é visto de modo autônomo e segregado da ética. Não se encontra, nos "Principios", a tentativa de definir a especificidade do fenômeno jurídico, ou de delimitar as fronteiras com a moral. É ele capítulo integrante da filosofia moral. ${ }^{17}$

Diferente é a situação da religião. Nesse ponto, reitera-se a separação já então milenar - pois construída na Escolástica - entre o sagrado e o direito. A título exemplificativo, cite-se o trecho em que Cairu critica os legisladores pátrios, que

haviam implicado as questões mercantis com improprias aplicações de Textos de Direito Civil e Canônico, e até com os princípios mais sagrados da religião, e influíram na exorbitância de todos os Estatutos sobre a usura, assim nacionais, como estrangeiros, fundados no erro que o dinheiro é a riqueza essencial dos Estados, que tem um valor fixo e permanente, e não pode produzir fruto algum civil. (CAIRU, 1817, p. 412).

\section{A.2. Direito integrado à Economia}

Seguindo os passos de Genovesi - cujos tratados de Economia eram estudados em Coimbra - e do Iluminismo Escocês de Hutchenson, Hume e Smith, Cairu igualmente inclui a economia no campo da filosofia moral, praticamente confundindo-a com o direito. Para Cairu, "a lei moral governa a vida econômica"18 e rege o comércio.

17 No campo moral, crê na natureza benigna do homem, criado à semelhança do criador. Daí suas críticas a Maquiavel e Rochefoucauld. V. "Um Moralista nos Trópicos”, de Pedro Meira Monteiro.

18 A subordinação da economia e do mercado à moral nada tem a ver com dirigismo econômico, nutrindo-se diretamente da doutrina de Adam Smith. Como adverte Wilson Martins, "o Tratado da Riqueza das Nações, 
Por sua vez, "a ciência do comércio compreende com muita especialidade a parte da jurisprudência, que expõe a natureza e os efeitos dos Contratos Mercantis". (CAIRU, 1817 , p. 535).

O autor publicou posteriormente obra intitulada "Leituras de Economia Política ou Direito Econômico".

Reitere-se, aliás, que os "Princípios de Economia Política" integrariam os "Principios de Direito Mercantil" como um oitavo tratado. Três quartos de século depois, na edição de 1874 dos "Principios", a segregação do direito e da economia está bem mais assentada. Cândido Mendes não reproduz em sua edição a oitava parte "por ter fraca relação com a matéria sujeita (...) não obstante dizer o autor no prefácio dos Estudos do Bem Comum que publicara tais princípios para animar o verdadeiro espírito comercial, como parte dos enunciados no Direito Mercantil. Em lugar, optou o editor por incluir obras que teriam maior conteúdo jurídico, como "Regras da Praça" e "Reflexões sobre o Comércio de Seguros".

Observe-se, no entanto, que a argumentação econômica e moral, embora presente nos princípios, tem um papel secundário face à invocação de fontes jurídicas, em especial dos alvarás e regimentos reais e das normas positivadas de outras nações.

\section{A.3. Função pedagógica do Direito}

Como consequência da visão do direito como elemento da filosofia moral, tem ele uma relevante dimensão pedagógica. Ademais, a pedagogia é uma preocupação chave do iluminismo setecentista.

O título completo da obra de Cairu era "Principios de Direito Mercantil e Leis de Marinha para uso da mocidade portugueza, destinada ao Commercio, divididos em oito tratados elementares, contendo a respectiva legislação patria, e indicando as fontes originaes dos regulamentos maritimos das principaes praças da Europa”.

Na página 11 do primeiro tratado, o autor reitera que o trabalho não e destinado aos sábios, "que consultam as fontes originais". Já no Tratado III, observa que "ainda que a presente Obra seja destinada para os principiantes na carreira mercantil, contudo pode servir de subsídio aos que se destinam ao ministério da advocacia e judicatura, suposto não possa encher, e menos fartar a sua curiosidade literária” (CAIRU, 1817, p. 311). Concluindo um dos tratados, reclama dos "sábios comunicação de luzes sobre os princípios especulativos da ciência do comércio" e dos "Senhores Negociantes

por consequência, só pode ser compreendido em sua natureza profunda à luz da Teoria dos Sentimentos Morais". (MARTINS, 2010, p. 33). 
versados nos conhecimentos teoréticos, e práticos, de sua profissão", contribuindo cada um "para a universalidade da instrução pública" (CAIRU, 1817, p. 220). ${ }^{19}$

Tal obra alcançava seu público. Os caixeiros portugueses do Rio de Janeiro tinham a obra de Cairu como principal material de sua preparação. O futuro Barão de Mauá, em seus primeiros passos, instruiu-se por Cairu, antes de ler Adam Smith (CALDEIRA, 1995, p. 118).

O foco pedagógico não tira o conteúdo normativo das postulações do autor, e nem compromete seu caráter instrumental, voltado a fortalecer a riqueza do reino e o crédito da monarquia. Por isso propõe em sua obra "um sistema de jurisprudência marítima, entrando na educação da Mocidade que se habilita a profissão do comércio, e próprio para engrandecer a esfera das especulações de tão útil classe de cidadãos". A perícia e a integridade dos negociantes são "principais molas" que dão movimento e vigor à indústria.

O padrão de conduta fixado por Cairu é o do homem ativo e probo, expressão que se incorpora de modo perene nas normas legais e na doutrina societária brasileira.

\section{A.4. Desprezo pelo Processo Judicial}

Tomando-se o direito como parte da filosofia moral, reforça-se seu papel de guia da conduta das partes, e não apenas de critério de decisão técnica em conflitos de interesses.

Cairu tem uma postura extremamente crítica quando ao processo judicial.

Em carta ao seu professor de Filosofia Natural de Coimbra, Domingos Vandelli, em 1781, após deixar o cargo de Ouvidor de Ilhéus, Lisboa reclama que vivia da "mendiga advocacia", "vida pouco análoga à constituição do meu gênio, era preciso que desamparasse inteiramente os estudos filosóficos para ir me perder nos profundos abismos das minúcias e formulários forenses”. (KIRSCHNER, 2009. p. 57).

Em sua obra, trata de modo relativamente sucinto das principais ações que "se movem entre comerciantes ou outras pessoas, que com eles trataram em seus negócios pertencentes a mercancia". A resolução mediante arbitragem, por equidade, seria o mais oportuno, se os homens não fossem tão propensos a contender.

Notam-se, ao longo dos Principios, inúmeras críticas ao processo judicial.

\footnotetext{
19 Endereçando a obra aos comerciantes, é com estes que Cairu polemiza. O negociante Manuel Luis de Veiga escreve "Reflexões Críticas sobre a Obra de José da Silva Lisboa intitulada Principios de Direito Mercantil por um Homem da Mesma Profissão”, em 1803, criticando-o acerbamente, em especial a afirmação de que, no seguro marítimo de navios negreiros, não se cobriria o sinistro de morte natural ou suicídios de escravos, o que exigiria que se oferecessem condições menos brutais para o transporte dos negros. De fato, Lisboa considerava doenças como vícios intrínsecos. (CAIRU, 1817, p. 60-61).
} 
Afirma que as causas mercantis exigem "a mais pura boa fé, equidade e prontidão nos despachos, não se embaraçando os comerciantes, e menos os navegantes, com litígios, discussões, e formalidades longas e tediosas, que se vem nos auditórios das Justiças Ordinarias", uma vez que "as dilações são muito prejudicais ao comércio" (CAIRU, 1817, p. 229). Em outros trechos, a linguagem é expressiva: "para apartar de si os riscos da navegação, é (o segurado) forçado a correr ainda maiores perigos no tempestuoso mar das cavilações do foro" (CAIRU, 1817, p. 27). Tratando da prova da fraude, afirma que o engano "sempre se esforça esconder nos labirintos e tortuosidades da trapaça forense". (CAIRU, 1817, p. 119).

3.B. Cairu: um jurista do "direito pátrio", na crise do antigo regime

3.B.1. A missão de organizar as fontes

As codificações do século XIX não se sucederam a um ius commune universal, característico da Idade Média. Entre esses momentos interpôs-se o chamado Direito Pátrio. O absolutismo foi acompanhado de um processo de fragmentação e regionalização do direito comum. O Direito Público, consistente nas ordenações régias - e que inclusive abarca o Direito Comercial, voltado à riqueza do Estado na concepção mercantilista-, passa gradualmente a ser ensinado nas universidades. Heinecio, jurista influente do século XVIII e autor muito citado por Cairu, defendia uma ciência jurídica uniforme, mas aceitava que os ordenamentos territoriais se diferenciassem. Percebe-se o direito como disciplina normativa precípua para a comunidade política, considerando-se a pátria fundada sobre uma base jurídica e institucional. Não se cuida apenas de privilegiar a lei real, mas também de compreender que a doutrina, a jurisprudência e os costumes tendiam a se particularizar.

Isso é percebido por Cairu: “Todos os mais Estados da Europa, que devem ao comércio a sua existência e consideração política, advertindo nos inconvenientes a que se sujeita a administração da justiça, quando do direito das partes se deixa a arbitraria discrição dos juízes, tem feito as suas ordenanças sobre matérias mercantis, apropriadas à natureza de sua constituição". (CAIRU, 1817, p. 9).

Insista-se que o particularismo não implicava o abandono na crença de princípios comuns e naturais, que se espelhariam nos vários sistemas locais. Não havia incompatibilidade entre jusnaturalismo e direito pátrio, pois a função deste era corrigir os costumes.

No direito pátrio, a doutrina tem um papel chave de organização das fontes.

Cairu compreendia perfeitamente seu papel de sistematizador do direito mercantil em Portugal, tal como fizera Mello Freire com o Direito Civil. 
Nos "Principios" o autor afirma que as matérias tratadas na obra estão "submergidas na imensidade e confusão dos Estatutos locais de diversas nações, e de contraditórios Arestos e decisões dos Escritores, e Tribunais Estrangeiros", devendo-se reconhecer "o quanto é árduo reduzir a princípios e sistema tão vagos e discordantes átomos, que se vem espalhando no vasto espaço de amontoados volumes sobre matérias de comércio, que mais assombram, e oprimem, do que alumiam”. Lisboa chama sua obra de "Ensaio", "que propõe, com alguma ordem, verdades úteis, e de frequente prática nas transações da vida, tirando-as do chão de volumosas obras, e constituindo-as ao nível de todos os espíritos, que se resolverem ao leve trabalho de uma lição pedagógica”. Seu ensaio "tem a vantagem de franquear alguns conhecimentos (...) que até agora eram recônditos nos gabinetes de poucos adeptos da alquimia mercantil, ou apenas giravam por informações confusas, e errôneas noções de sua natureza e efeitos". (CAIRU, 1817, p. 220).

Registre-se que as críticas ao direito comum eram habituais no jusnaturalismo. (LOPES, 2004, p. 60).

No tratado sobre contratos, recomenda os autores clássicos "Só ofereci Principios de Direito Mercantil. Cumprirei o prometido" (CAIRU, 1817, p. 535).

Os tratados não se organizam sob o prisma do sujeito de direito individual abstrato e individualizado, mas a partir de problema concretos do dia a dia mercantil, adotando um método indutivo, que era comum no Direito Comercial, em contraste ao Direito Civil.

\section{B.2. A espera pelo direito régio}

$\mathrm{Na}$ dedicatória dos "Principios" ao Príncipe Regente, Lisboa afirma "o desejo de fazer ao Estado algum serviço durável", contribuindo para a "extensão e prosperidade do Comércio Nacional". Falta "um ensaio de literatura deste gênero em linguagem pátria". Sua doutrina assume-se como fonte de direito, mas enquanto se esperam regimentos e decisões de tribunais. Lisboa espera que sua obra possa "acelerar a publicação de um Código Marítimo, que contenha os princípios desta Jurisprudência universal". (CAIRU, 1817, p. 12). De igual modo, no tratado segundo, que versa sobre câmbio marítimo, afirma justificar-se o ensaio pela "falta de legislação pátria para a decisão de todos os casos e controvérsias". (CAIRU, 1817, p. 261).

Nesse momento imediatamente anterior às grandes codificações, já há a percepção de ser a lei a fonte do direito por excelência, mas não se nega à doutrina a mesma função de fonte. A própria lei, quando editada, afirma revogar a doutrina que lhe seja contrária, como se infere do Alvará de 1757 que restringe a cobrança de juros, salvo para comércio com a Índia, que, em seu trecho final, afirma: "Hei por bem derrogar de 
meu motu próprio, certa ciência, Poder Real pleno e supremo, todas as leis, disposições de direito comum, e opiniões de Doutores em contrário, ficando aliás sempre em seu vigor". ${ }^{20}$

Assenta-se a preponderância do ato de vontade do detentor do poder político como fonte primaria, relegando-se a posição secundária os costumes e a doutrina. ${ }^{21}$

O tema do comércio, portanto, era tido como próprio do Direito Público, definido como direito regido por leis régias. Assim, por exemplo, afirma que o seguro pode ser contratado "dentro ou fora da Nação" desde que "não viole o direito público da Europa, nem as leis do país" (CAIRU, 1817, p. 27). Começa-se a ver a noção de lei como restrição da liberdade no interesse público, tal como no direito moderno:

Segundo o direito natural, não há repugnância alguma de poder qualquer pessoa fazer as funções de segurador (...) O que porém é lícito por Direito Natural, não é sempre permitido por Direito Civil, que considera os homens ligados a certos deveres da sociedade, onde o soberano pode, por justos motivos, restringir o exercício do domínio, e liberdade individual, a termos conciliários com o interesse do público. (CAIRU, 1817, p. 23).

\section{B.3. O papel do Ius Gentium e do Comércio}

A afirmação da lei como fonte primária do direito não implica uma concepção decisionista. A lei deve se guiar pela razão e pela natureza, corrigindo os costumes.

$\mathrm{O}$ direito nutre-se da sociabilidade natural das pessoas, em uma visão organicista e coletiva da sociedade, de base aristotélico-tomista, com repúdio às teorias contratualistas e individualistas.

Assim, os contratos mercantis ligam-se ao "instinto para a troca" (CAIRU, 1817, p. 535) e têm "essências": "a essência deste contrato (de câmbio marítimo), e segundo as regras de direito civil, consiste no risco marítimo, que real e efetivamente corre por sua conta o que deu algum soma para a específica viagem". (CAIRU, 1817, p. 266). Fruto de inclinação natural, "as sociedades se contraem na confiança da amizade (...) os sócios se consideram como irmãos”. (CAIRU, 1817, p. 588).

20 Cairu critica tal alvará, mas com grande reverência, nesses termos: "Protestando a mais religiosa reverência às Leis Pátrias, todavia parecer que se faz urgente a Reforma ou Declaração Autêntica do Alvará de 17 de janeiro de 1757, pelas observações que, com o mais profundo acatamento, submeto à sabedoria do Governo, e sua tão paternal, e esclarecida proteção do comércio e navegação". Afirma que o alvará está "imbuído dos erros do sistema mercantil de Colbert", depois das luzes da obra do "Grande mestre Smith". (CAIRU, 1817, p. 284).

21 A distinção assim estabelecida entre fonte primária e secundária é afirmada por Coelho da Rocha e, posteriormente, por Antonio Joaquim Ribas. (LOPES, 2004, p. 129/130). 
Fundado nessa sociabilidade, o comércio é "grande princípio vivificante da máquina social”. "Constitui uma só família o corpo mercantil de todas as nações, parte especial do direito das gentes". (CAIRU, 1817, p. 123). Mais ainda: "o Vínculo do comércio faz de todos os povos uma só família”. (CAIRU, 1817, p. 158).

Por isso, de modo natural, em matéria de navegação e comércio, a legislação dos diferentes países é coerente, compondo o direito das gentes. Afirma Cairu que " $O$ contrato de câmbio é de direito das gentes; porque o uso, e necessidade do comércio o tem feito comum a todas as nações, e por isso, os Estatutos e Costumes locais a esse respeito são idênticos na substância, apenas variando em coisas acidentais”.

Conclusão

No prefácio endereçado "Ao Leitor", da edição de 1874 dos "Principios de Direito Mercantil" de Cairu, Cândido Mendes de Almeida diz que, em matéria de doutrina, "estamos avassalados pelo estrangeiro".

Descontando-se o nacionalismo romântico da época, a advertência é oportuna. O desenvolvimento dos estudos jurídicos no Brasil exige que, mais do que papaguear doutrinas estrangeiras, compreendamos nossa produção passada.

Essa compreensão há de se fazer em seus próprios termos. A obra dos juristas brasileiros deve ser entendida em seu contexto, dando-se aos conceitos chave a semântica que lhes era contemporânea, e atentando-se para as rupturas e descontinuidades. Doutrinadores do século XXI não dialogam com os do século XIX utilizando as mesmas referências, não obstante a identidade da língua.

O emprego adequado de métodos da historiografia do direito para a análise das obras doutrinárias do passado permitirão iluminar o próprio sentido das fontes e práticas jurídicas pretéritas, e funcionarão de elo para se vincular a história das instituições e das ideias com a história dos juristas como grupo social.

Finalmente, a percepção das rupturas e a reencenação das ideias do passado - para se empregar o termo caro a Collingwood - nos ajudará a identificar também as continuidades e os campos em comum que compartilhamos com esses juristas oitocentistas, já que somos herdeiros dessa mesma tradição, e ainda temos o que aprender com eles.

São Paulo, maio de 2017. 


\section{Referências}

ALMEIDA, Candido Mendes de. Introducção. In: CAIRÚ, José da Silva Lisboa, Visconde de. Principios de direito mercantil e leis de marinha divididos em sete tratados elementares, contendo a respectiva legislação patria, e indicando as fontes originaes dos regulamentos maritimos das principaes praças da Europa. 6. ed. Rio de Janeiro: Typographia Academica, 1874. v. 1, p. 19 a 448.

ATHAYDE, Tristão de. [Alceu Amoroso Lima]. Época, vida e obra de Cairu. In: CAIRÚ, José da Silva Lisboa, Visconde de. Princípios de economia política. Rio de Janeiro: Pongetti, 1956. p. 1543.

BIROCCHI, Italo; MATTONE, Antonello. Il diritto pátrio. Tra diritto comune e codificazione (Secoli XVI-XIX). A cura di Italo Birocchi e Antonello Mattone. Roma: Viella, 2006.

CABRAL, Alfredo do Valle. Vida e escriptos de José da Silva Lisboa, visconde de Cayrú. Rio de Janeiro: Typographia Nacional, 1881.

CAIRU, José da Silva Lisboa. Constituição moral e deveres do cidadão: com exposição da moral pública conforme o espírito da constituição do império. João Pessoa: Editora Universitária da UFPB, 1998.

. Principios de direito mercantil e leis de marinha. 6. ed. por Candido Mendes de Almeida. Rio de Janeiro: Livraria Acadêmica, 1874. 2 v.

- Principios de direito mercantil e leis de marinha. Lisboa: Imprensa Regia, 1815.

Reimpressão fac-símile pelo Serviço de Documentação do Ministério da Justiça e Negócios Interiores, Rio de Janeiro, 1963.

. Princípios de economia politica. Rio de Janeiro: Pongetti, 1956.

CALDEIRA, Jorge. Mauá: Empresário do Império. São Paulo: Companhia das Letras, 1995.

COSTA, Salustiano Orlando de Araújo. Codigo commercial do Imperio do Brazil. 4. ed. Rio de Janeiro: Laemmert \& C Editores, 1886.

DANTAS, Francisco Clementino San Tiago. Cairu. Protagonista de sua época. In: DANTAS, Francisco Clementino de San Tiago. Figuras do direito. Rio de Janeiro: Forense, 2002. p. 1 a 24.

FARIA, Antonio Bento de. Codigo commercial brazileiro. 1. ed. Rio de Janeiro: Jacinto Ribeiro dos Santos, 1903.

. Codigo commercial brasileiro. 4. ed. Rio de Janeiro: Jacinto Ribeiro dos Santos, 1929.

FERREIRA, Waldemar. Tratado de direito comercial. São Paulo: Saraiva, 1960. v. 1.

FREITAS, Augusto Teixeira de. Additamentos ao codigo do commercio. Rio de Janeiro: Tipografia Perseveranca, 1878. 2 v. 
FURTADO, Celso. Formação econômica do Brasil. 27. ed. São Paulo: Companhia Editora Nacional, Publifolha, 2000.

HOLANDA, Sérgio Buarque de. Raizes do Brasil. 23. ed. Rio de Janeiro: José Olympio Editora, 1991.

KIRSCHNER, Tereza Cristina. José da Silva Lisboa. Visconde de Cairu: itinerários de um ilustrado luso-brasileiro. São Paulo: Alameda, Belo Horizonte: PUC Minas, 2009.

LAMY, José Alfredo. A reedição de Cairu. In: CAIRU, José da Silva Lisboa. Princípios de direito mercantil e leis de marinha. [Rio de Janeiro]: Serviço de Documentação do M. J. N. I., 1963. (Facsimile reproduction of the 1815 edition).

LOPES, José Reinaldo de Lima. As Palavras e a Lei: direito, ordem e justiça na história do pensamento jurídico moderno. São Paulo: Editora 34, 2004. (Coleção Direito GV).

LUSTOSA, Isabel. Insultos Impressos: a guerra dos jornalistas na independência, 1821-1823. São Paulo: Companhia das Letras, 2000.

MARTINS, Wilson. História da inteligência brasileira. 3. ed. Ponta Grossa: Editora UEPG, 2010. v. 2 (1794-1855).

MENDONÇA, José Xavier Carvalho de. Tratado de Direito Commercial Brasileiro. Rio de Janeiro: Freitas Bastos, 1937. v. 1.

MONTEIRO, Pedro Meira. Um moralista nos trópicos: o Visconde de Cairu e o Duque de La Rochefoucauld. São Paulo: Boitempo, 2004.

MONTENEGRO, João Alfredo de Sousa. O discurso autoritário de Cairu. Brasília: Senado Federal, 2000.

OLIVEIRA, Brasílio Augusto Machado de. O Codigo Commercial do Brasil. Subsidios historicos de sua formação. Revista da Faculdade de Direito de São Paulo, São Paulo, v. 17, p. 9-56, jan./ dez. 1910.

PAIM, Antonio. Cairu e o liberalismo econômico. Rio de Janeiro: Tempo Brasileiro, 1968.

RAMOS, Joaquim José Pereira da Silva. Abecedario juridico-commercial: ou compilação por ordem alphabetica das disposições actualmente em vigor do codigo commercial do Imperio do Brasil. Rio de Janeiro: Eduardo \& Henrique Laemmert, 1861.

ROCHA, Antonio Penalves. Introdução. In: ROCHA, Antonio Penalves. (Org.). José da Silva Lisboa, Visconde de Cairu. São Paulo: Editora 34, 2001. (Coleção Formadores do Brasil).

SOUZA, Herculano Inglez de. Direito commercial. 2. ed. Compiladas pelo bacharel Alberto Biolchini, Rio de Janeiro: Francisco Alves, 1910. 
VARNHAGEN, Francisco Adolfo de. História geral do Brasil: antes da sua separação e independência de Portugal. 7. ed. Belo Horizonte: Itatiaia, Edusp, 1981. v. 3, t. 5.

WIEACKER, Franz. História do direito privado moderno. Lisboa: Fundação Calouste Gulbenkian, 1980. 